\title{
Extracellular Vesicle Formation and Biosurfactant Production by Serratia marcescens
}

\author{
By TOHEY MATSUYAMA, ${ }^{1}{ }^{*}$ TSUKASA MURAKAMI, ${ }^{2}$ \\ MASASHI FUJITA, ${ }^{1}$ SHIGERU FUJITA ${ }^{1}$ AND IKUYA YANO ${ }^{1}$ \\ 'Department of Bacteriology, Niigata University School of Medicine, Niigata 951, Japan \\ ${ }^{2}$ Department of Virology, Osaka City Institute of Public Health and Environmental Sciences, \\ Osaka 543, Japan
}

(Received 23 July 1985; revised 24 October 1985)

\begin{abstract}
Pigmented and non-pigmented strains of Serratia marcescens produced extracellular vesicles and had wetting activity when grown at $30^{\circ} \mathrm{C}$ but not at $37^{\circ} \mathrm{C}$. Light microscopy showed that the red pigment was present in vesicles and intracellular granules. Electron microscopy revealed the presence of vesicles surrounded by the bacterial membrane. Three lipids having the wetting activity, W1, W2 and W3, were isolated by thin-layer chromatography of lipids from different strains of $S$. marcescens. Dispersions of the isolated wetting agents had small contact angles on a polystyrene surface and the ability to lower surface tension. Wetting agent Wl was the aminolipid serratamolide. Wetting agents $\mathrm{W} 2$ and $\mathrm{W} 3$ were also aminolipids but were shown to be different from serratamolide by chemical analyses. Wetting agent and prodigiosin (in a pigmented strain) were the main lipids of isolated vesicles.
\end{abstract}

\section{INTRODUCTION}

During routine preparation of smears for Gram staining, we noted the strange behaviour of a suspension containing Serratia marcescens. On the clean surface of a glass slide, a drop of the suspension spread instantaneously (Matsuyama et al., 1985). This phenomenon, known as 'spreading wetting' in physical chemistry, suggested the presence of a biosurfactant acting as a wetting agent. After surveying many species of bacteria, we realized that this wetting activity was a unique characteristic of $S$. marcescens. As reported previously (Matsuyama et al., 1985), the compound having the wetting activity was isolated from $S$. marcescens strains ATCC 13880 and NS 38, and identified as an aminolipid identical to serratamolide which had been reported as an antibiotic from $S$. marcescens (Wasserman et al., 1961, 1962).

Optical microscopic examination of unstained bacterial suspensions having the wetting activity revealed the presence of many extracellular vesicles and cells carrying 'half vesicles' presumed to be in the course of vesicle formation. In pigmented strains, the red colour seemed to be localized in such vesicles. Many strains of $S$. marcescens grown at $30^{\circ} \mathrm{C}$ had the wetting activity and formed extracellular vesicles. The same strains grown at $37^{\circ} \mathrm{C}$, however, did not have the wetting activity or form the extracellular vesicles. The new features of $S$. marcescens revealed by analyses of these findings are described in this paper.

\section{METHODS}

Bacterial strains and growth. Pigmented strains (NS 12, NS 38 and NS 78) and non-pigmented strains (NS 13, NS 25, NS 33 and NS 45) of $S$. marcescens were laboratory stocks of the Department of Bacteriology, Niigata University School of Medicine (Matsuyama et al., 1985) and shown to be in the rank of 'very good identification' by the recent Analytab API 20E system. Colour mutant strains 933 and WF of S. marcescens were kindly provided by Dr R. P. Williams, Baylor College of Medicine, Houston, USA. S. marcescens ATCC 13880, Serratia liquefaciens ATCC 27592, NCTC 10442 and CDC 1284-57, Serratia rubidaea ATCC 27593 and CDC 299-72, Pseudomonas aeruginosa ATCC 10145, Pseudomonas fluorescens IFO 14160 and Pseudomonas cepacia ATCC 25416 were kindly 
supplied by Dr E. Yabuuchi, Gifu University School of Medicine, Gifu, Japan. S. marcescens ATCC 8100, Enterobacter cloacae ATCC 23355, Klebsiella pneumoniae ATCC 13883, Proteus vulgaris ATCC 13315 and Escherichia coli ATCC 25922 were obtained from Difco. E. coli K12 S and W 3110 and Salmonella typhimurium LT-2 were laboratory stocks. All strains, except $S$. rubidaea CDC 299-72 which was grown at $27^{\circ} \mathrm{C}$, were grown at $30^{\circ} \mathrm{C}$ or $37^{\circ} \mathrm{C}$ for $3 \mathrm{~d}$ on a peptone/glycerol (PG) agar medium (Matsuyama et al., 1985).

Examination of surface activity. The wetting activity on a glass surface (Pre-Cleaned Micro Slide Glass, Matsunami, Japan) was examined as described previously (Matsuyama et al., 1985). For quantitative estimation of the wetting activity, $2 \mu \mathrm{l}$ of the supernatant of a bacterial suspension $\left(10 \mathrm{mg} \mathrm{ml}^{-1}\right)$ or $2 \mu \mathrm{l}$ of a lipid dispersion $\left(2 \mathrm{mg} \mathrm{ml}^{-1}\right.$, prepared by sonication for a few minutes at $90^{\circ} \mathrm{C}$ ) was spotted on a polystyrene surface. The diameters of 10 droplets of each sample at room temperature were measured microscopically. The contact angle on a polystyrene surface was calculated from the mean droplet diameter as described by Mack (1935). The ability to lower surface tension was examined by adding $250 \mu \mathrm{l}$ of lipid dispersion in saline $\left(2 \mathrm{mg} \mathrm{ml}^{-1}\right.$, prepared as described above) to the surface of $50 \mathrm{ml}$ saline in a modified Wilhelmy balance (Acoma, Japan) and measuring the surface tension by changing the surface area from $40 \mathrm{~cm}^{2}$ to $12 \mathrm{~cm}^{2}$ (Kobayashi et al., 1984; Matsuyama et al., 1985).

Isolation of extracellular vesicles. A bacterial suspension containing extracellular vesicles was treated with $2.5 \%$ $(\mathrm{v} / \mathrm{v})$ glutaraldehyde for $1 \mathrm{~h}$ at $4{ }^{\circ} \mathrm{C}$, and centrifuged at $2000 \mathrm{~g}$ for $30 \mathrm{~min}$. After removing the foamy upper layer the supernatant was recentrifuged $(2000 \mathrm{~g}, 10 \mathrm{~min})$. The translucent supernatant was then centrifuged at $20000 \mathrm{~g}$ for $90 \mathrm{~min}$. The pellet was composed mostly of small vesicles.

Electron microscopy. For scanning electron microscopy, bacteria were dried on a glass slip (4 $\times 4 \mathrm{~mm}$ ), fixed in $2 \%(\mathrm{v} / \mathrm{v})$ glutaraldehyde in $0.1 \mathrm{M}$-cacodylate buffer $(\mathrm{pH} 7.4)$ for $30 \mathrm{~min}$ at $4{ }^{\circ} \mathrm{C}$, washed in cacodylate buffer and post-fixed in $1.0 \%(\mathrm{w} / \mathrm{v}) \mathrm{OsO}_{4}$ in cacodylate buffer for $30 \mathrm{~min}$ at $4{ }^{\circ} \mathrm{C}$. The specimens were dehydrated and criticalpoint dried as described previously (Matsuyama, 1977), and coated with gold by sputtering in an ion bombardment apparatus (JFC-1 100, JEOL). Observations were made with a JSM-840 microscope (JEOL). For transmission electron microscopy, wet bacterial mass was fixed as described previously (Murakami \& Matsuyama, 1980). After dehydration in ethanol, the bacterial mass was placed in propylene oxide and embedded in Epon 812. Thin sections were cut using an ultramicrotome with a diamond knife. The sections were stained with uranyl acetate and lead citrate, and examined with an electron microscope (JEM-100B; JEOL). Specimens were negatively stained on carbon-coated grids with $2 \%(\mathrm{w} / \mathrm{v})$ phosphotungstic acid ( $\mathrm{pH} 7 \cdot 0$ ).

Chemical analyses. Wet bacterial mass from the surface of agar was directly extracted with 10 vols ethanol. After removal of sediment by centrifugation and ethanol by evaporation, the dry material was further extracted with chloroform/methanol $(2: 1, \mathrm{v} / \mathrm{v})$. The extracts were examined on a thin-layer chromatography (TLC) plate of silica gel $G$ (Analtech) in a solvent system, chloroform/methanol/5 M-ammonia $(80: 25: 4$, by vol.). After visualization with iodine vapour, the separated bands were scraped off, extracted with chloroform $/ \mathrm{methanol}(2: 1, \mathrm{v} / \mathrm{v})$ and examined for their wetting activity. Acid hydrolysis and methanolysis of the active compounds and analysis by TLC and gas chromatography/mass spectrometry (GC/MS) were carried out as described previously (Ohno et al., 1976; Kawai \& Yano, 1983; Matsuyama et al., 1985). IR spectra of samples as KBr discs were recorded with a Nihonbunko model DS-402G apparatus.

\section{RESULTS}

\section{Wetting activity and extracellular vesicles}

A small amount of bacterial mass from colonies of $S$. marcescens (e.g. strain NS 38) grown at $30^{\circ} \mathrm{C}$ was mixed with a drop of water on a clean glass surface. The suspension immediately demonstrated an extraordinary wetting activity by spreading spontaneously on the glass surface, giving a characteristic shape on drying (Fig. 1a). An optical micrograph of the spreading end showed red granular material surrounding the cluster of colourless bacterial cells (Fig. 2).

Direct observation of the bacterial suspension having the wetting activity with a phasecontrast microscope revealed the presence of many extracellular vesicles $(0.1-3.0 \mu \mathrm{m}$ in diameter), and vesicles associated with bacterial cells (Fig. $3 a$ ). Further, by bright-field illumination of the same microscopic field, the native distribution of red pigment in the culture of pigmented strains (NS 12, NS 38 and NS 78) could be examined. The red pigment was localized in such vesicles or intracellular granules, whereas the bacterial cells were colourless (Fig. $3 b$ ). In the type strain ATCC 13880, which had the wetting activity but produced no extracellular vesicles, intracellular granules and vesicles half-protruding from cells were redcoloured. Non-pigmented strains NS 25, NS 33 and NS 45 also had the wetting activity and formed extracellular vesicles in spite of the absence of pigment. Colour mutants 933 and WF or 


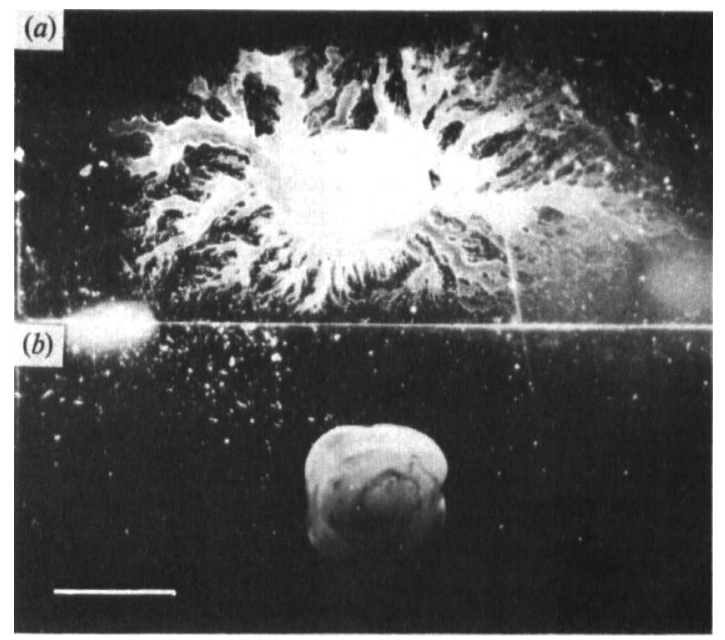

Fig. 1. Wetting activity of $S$. marcescens NS 38 on a glass surface. $(a) 30^{\circ} \mathrm{C}$ culture; (b) $37^{\circ} \mathrm{C}$ culture. Bar, $10 \mathrm{~mm}$.

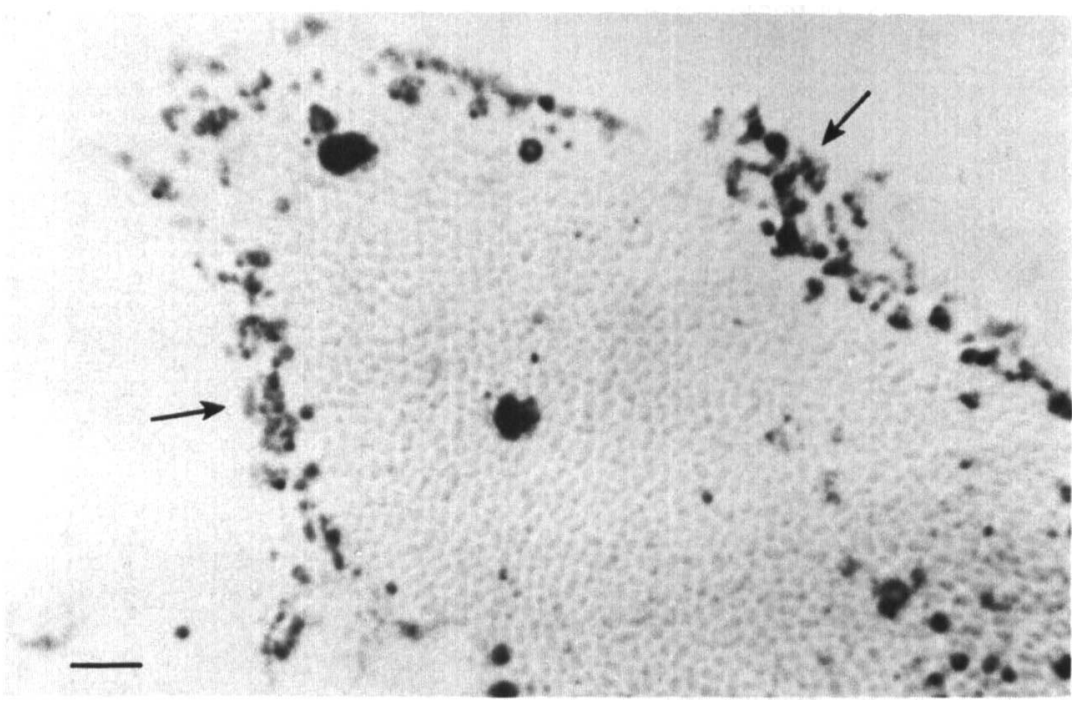

Fig. 2. Suspension of $S$. marcescens NS 38. Micrograph of unstained spreading end. Arrows indicate red granular material surrounding the bacterial cells. Bar, $5 \mu \mathrm{m}$.

non-pigmented strains ATCC 8100 and NS 13 had weak wetting activity and no extracellular vesicle formation. Among 15 strains of other species (see Methods), S. rubidaea ATCC 27593 and CDC 299-72 had the wetting activity and formed extracellular vesicles. Other strains were completely devoid of these properties.

For development of wetting activity and extracellular vesicles, the growth temperature was important. The $S$. marcescens strains and $S$. rubidaea ATCC 27593 grown at $37^{\circ} \mathrm{C}$ hardly had any wetting activity (Fig. 1 b) and extracellular vesicle formation (Fig. $3 c$ ) at any culture age. In the $S$. marcescens and $S$. rubidaea strains, the loss of wetting activity was always accompanied by disappearance of the extracellular vesicles.

Wetting activity of $S$. marcescens on a glass surface was confirmed by measuring the contact angles of droplets on a polystyrene surface (Table 1). In contrast with E. coli, S. marcescens had small $\left(30^{\circ} \mathrm{C}\right.$ culture $)$ or large $\left(37^{\circ} \mathrm{C}\right.$ culture) contact angles in accordance with the presence or the absence of the wetting activity. 

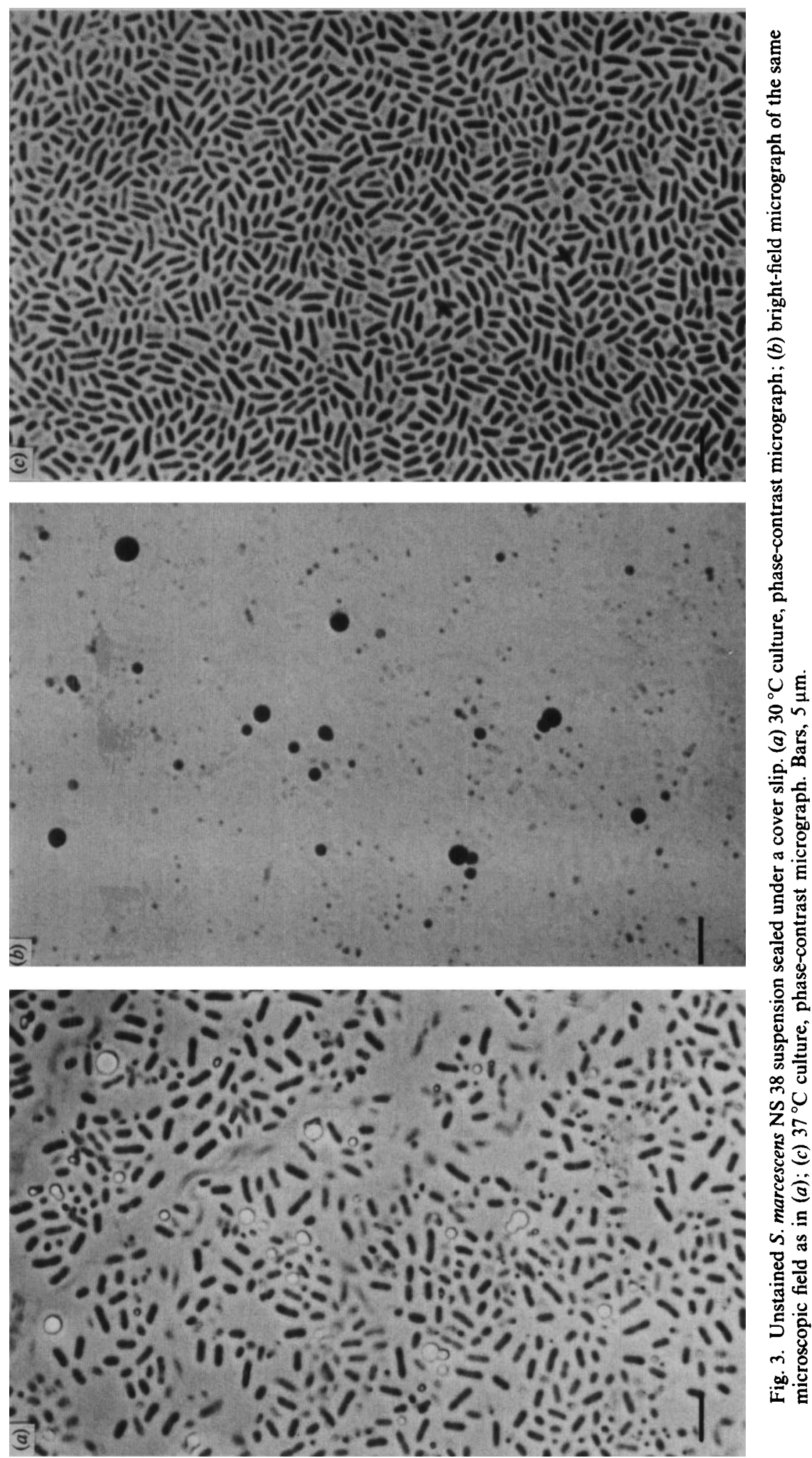

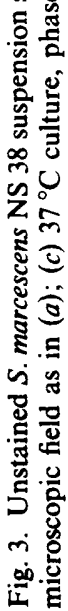


Table 1. Contact angles of droplets of cell supernatants on a polystyrene surface

$\begin{array}{lcc}\quad \begin{array}{c}\text { Bacterial } \\ \text { strain }\end{array} & \begin{array}{c}\text { Growth } \\ \text { temp. }\left({ }^{\circ} \mathrm{C}\right)^{*}\end{array} & \begin{array}{c}\text { Contact angle } \\ (\theta) \dagger\end{array} \\ \text { Saline (control) } & & 82.0 \pm 1.6 \\ \text { E. coli } \text { K12 S } & 30 & 76.8 \pm 2.2 \\ & 37 & 76.0 \pm 1 \cdot 1 \\ \text { S. marcescens NS 38 } & 30 & 19.8 \pm 0.4 \\ & 37 & 69.4 \pm 1.0 \\ \text { S. marcescens NS 25 } & 30 & 21.8 \pm 0.5 \\ & 37 & 69.6 \pm 0.9 \\ \text { S. marcescens NS 45 } & 30 & 17.9 \pm 0.5 \\ & 37 & 66.6 \pm 0.9\end{array}$

* The strains were grown for $3 \mathrm{~d}$ on a PG agar medium at the indicated temperature. Supernatants $(2 \mu l)$ of the bacterial suspensions were spotted on a polystyrene surface.

$\dagger$ Obtained by the method of Mack (1935); values are means of 10 determinations \pm SEM.

\section{Electron microscopic examination}

Vesicle formation by $S$. marcescens at $30^{\circ} \mathrm{C}$ was also observed by electron microscopy. After growth at $37^{\circ} \mathrm{C}$, on the other hand, vesicles were only occasionally seen and were smaller (data not shown). Scanning electron microscopy and negative-staining showed that vesicles around bacterial cells seemed to be 'blebbing' from the cell surface (Figs $4 a$ and $4 b$ ). Transmission electron microscopy of ultrathin sections (Figs 5 and 6) revealed the characteristic architecture of these vesicles. Some were full of amorphous material (A in Fig. 5), whereas others carried a part of the bacterial cytoplasm (B in Fig. 5). Some cells contained a drop of dense amorphous material in the cytoplasm (C in Fig. 5). Vesicle formation seemed to be coupled with excretion of the amorphous material, and bacterial cells believed to be in the process of vesicle formation were frequently observed (Fig. 6). The membrane extending from the outer membrane of the bacterial cell seemed to participate in vesicle formation.

\section{Bacterial products responsible for wetting activity}

Wetting activity was recognized in dried ethanol extracts, but not in sedimented bacterial cells. The ethanol extracts were further extracted with chloroform/methanol and examined by TLC. Behind the fastest running spot of the red pigment having an absorption spectrum identical to that of prodigiosin in acidic and alkaline ethanol, three spots (W1, W2 and W3, Fig. 7) were observed in $S$. marcescens strains. The isolated lipids corresponding to spot W1 of pigmented strain NS 38, spot W2 of non-pigmented strain NS 25 and spot W3 of nonpigmented strain NS 45 had strong wetting activity.

In contrast to the extracts from $37^{\circ} \mathrm{C}$ cultures, those from $30^{\circ} \mathrm{C}$ cultures gave a large specific spot having the wetting activity (lanes 1 and 2 in Fig. $8 a, b$ ). In addition, the greatly reduced amounts of phospholipids from the lipids of $30^{\circ} \mathrm{C}$ cultures was noteworthy. The spot of phosphatidylethanolamine was still faint even after application of $500 \mu \mathrm{g}$ lipid extracts from $30^{\circ} \mathrm{C}$ culture (data not shown). On comparative TLC of extracts from $30^{\circ} \mathrm{C}$ and $37^{\circ} \mathrm{C}$ cultures, other strains of $S$. marcescens had similar differences corresponding to the changes in wetting activity.

\section{Assay of the surfactant activity}

Isolated wetting agents were dispersed in saline by sonication. The contact angles of these dispersions on a polystyrene surface and their abilities to lower the surface tension of saline were examined (Table 2). Even on a polystyrene surface, the diameter of droplets of dispersions of W2 or W3 increased gradually, so the contact angles of these droplets were expected to become smaller than the values given in Table 2. 


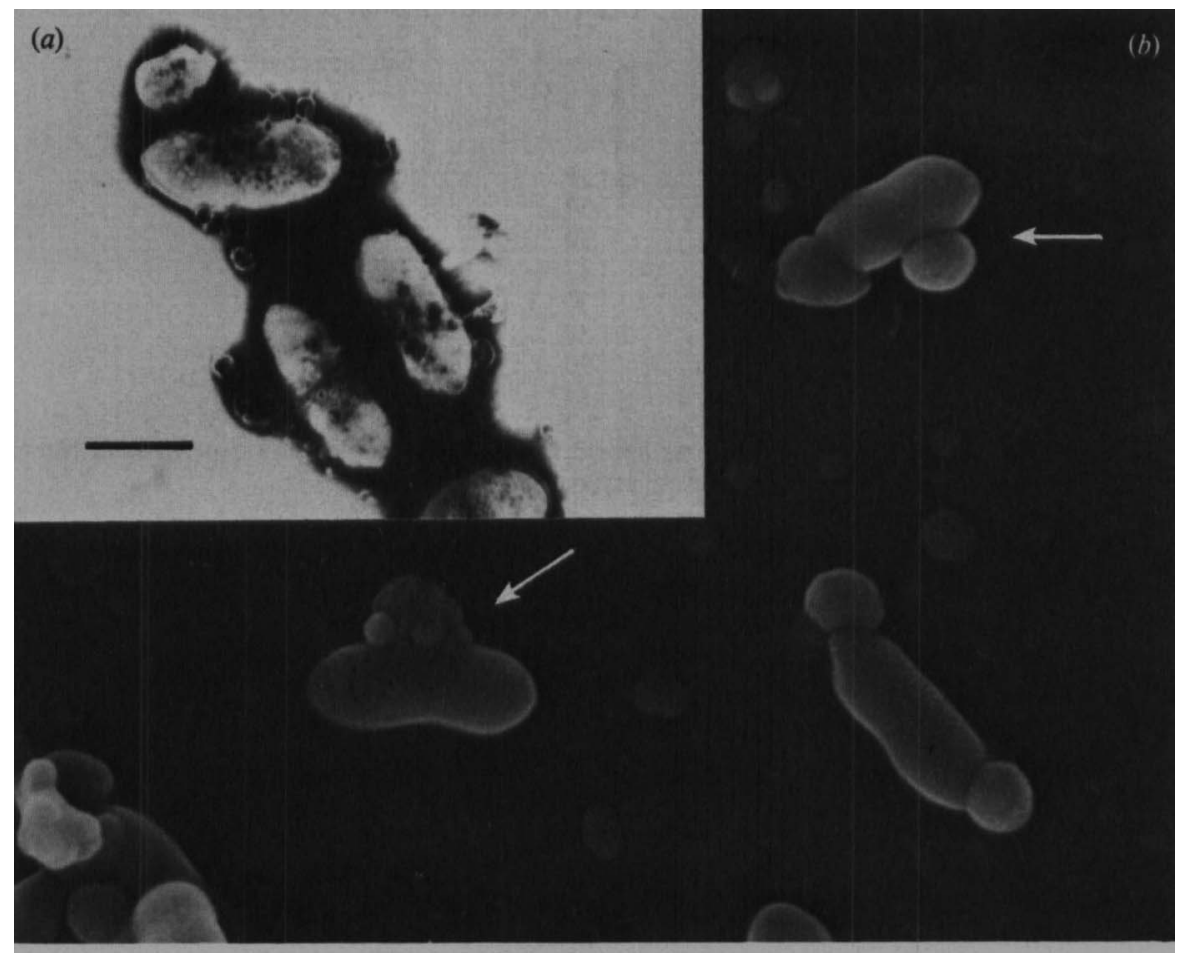

Fig. 4. Electron micrographs of S. marcescens NS 38 grown at $30^{\circ} \mathrm{C}$. (a) Negative-stained micrograph; (b) scanning electron micrograph. Arrows indicate cell-associated spherical bodies. Bar, $1 \mu \mathrm{m}$.

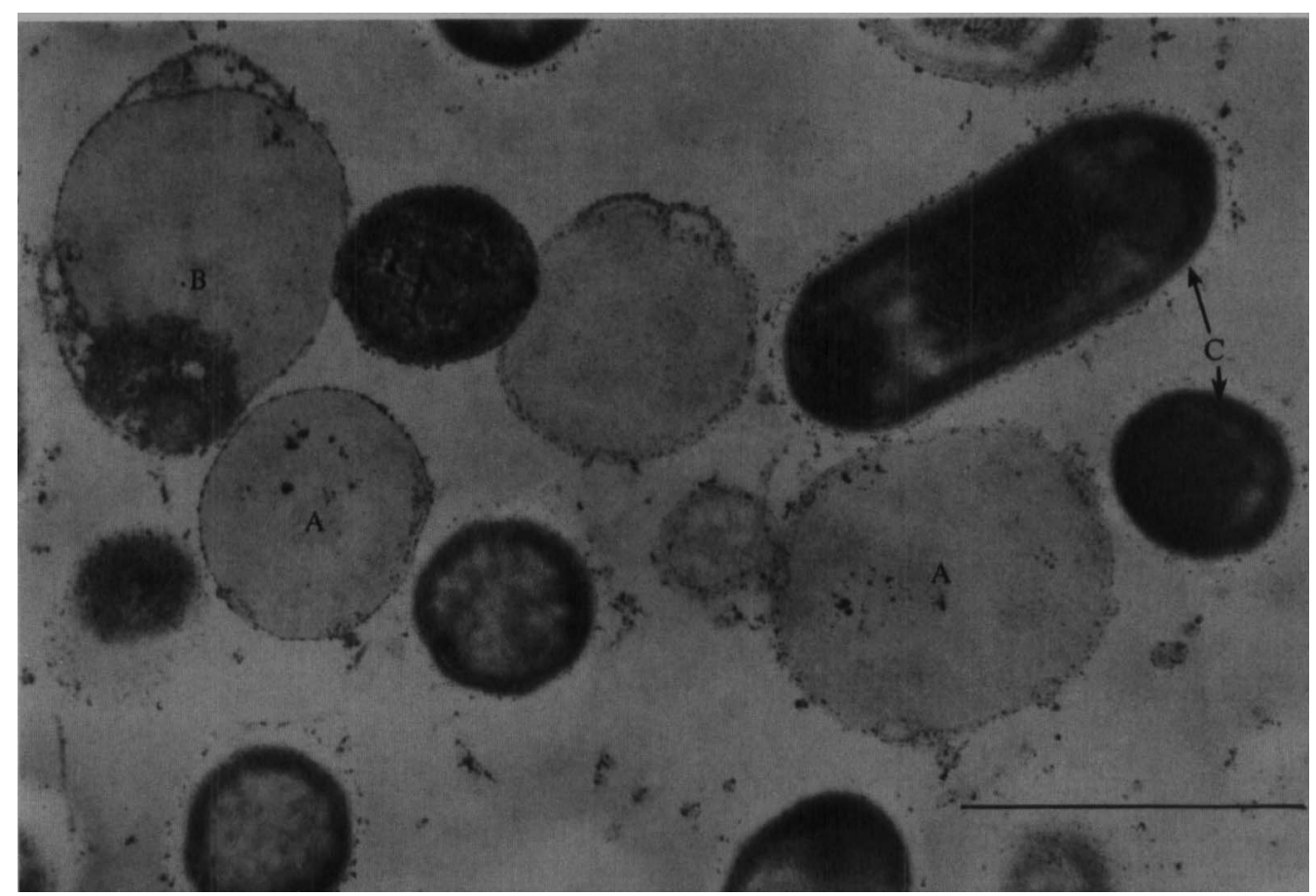

Fig. 5. Thin-section electron micrograph of $S$. marcescens NS 38 grown at $30^{\circ} \mathrm{C}$. A, vesicles full of amorphous material; B, a vesicle carrying bacterial cytoplasm; $\mathrm{C}$, intracellular drops. Bar, $1 \mu \mathrm{m}$. 


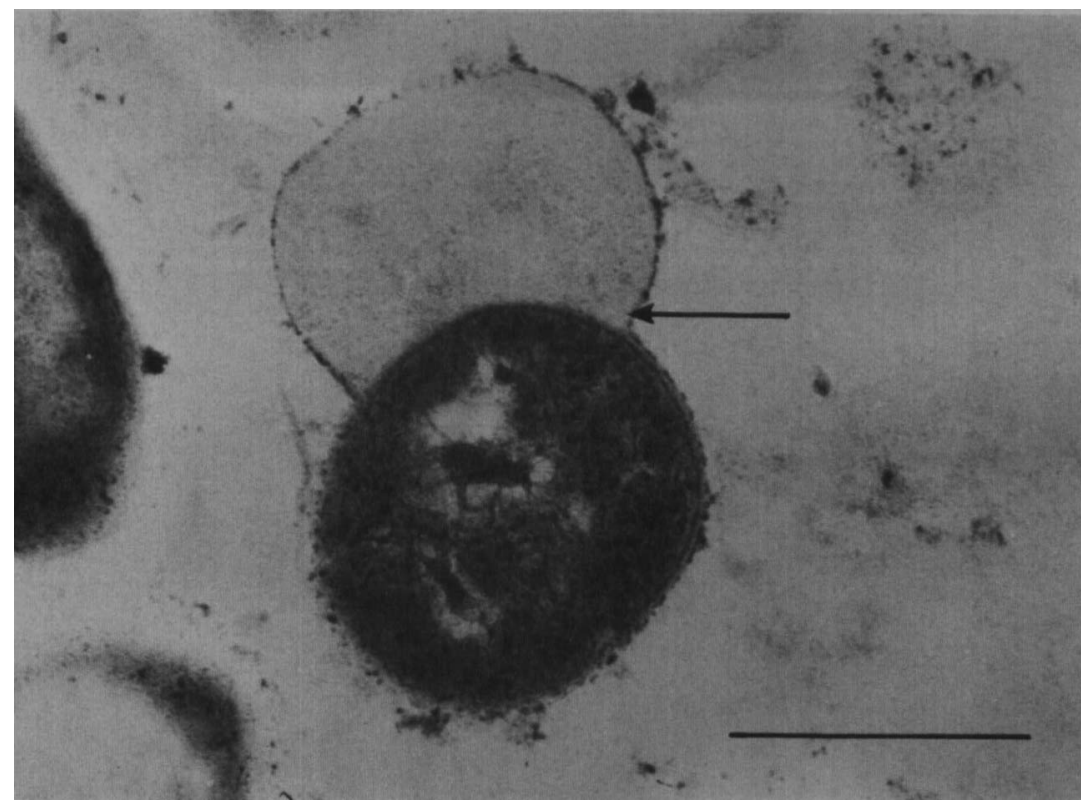

Fig. 6. Thin-section electron micrograph of $S$. marcescens $\mathrm{NS} 38$ grown at $30^{\circ} \mathrm{C}$. The arrow indicates extending outer membrane. Bar, $0.5 \mu \mathrm{m}$.

Table 2. Surface activities of $S$. marcescens wetting agents

$\begin{array}{lcc}\text { Wetting agent } & \begin{array}{c}\text { Surface tension } \\ \left(\mathrm{m} \mathrm{N} \mathrm{m}^{-1}\right)^{*}\end{array} & \begin{array}{c}\text { Contact angle } \\ (\theta) \dagger\end{array} \\ \text { W1 }(\text { S. marcescens NS 38) } & 32.2 \pm 0.1 & 29.3 \pm 0.6 \ddagger \\ \text { W2 }(S \text {. marcescens NS 25) } & 33.9 \pm 0.2 & <11.6 \S \\ \text { W3 }(S \text {. marcescens NS 45) } & 28.8 \pm 0.3 & <9.4 \S\end{array}$

* The values (means $\pm \mathrm{SEM}, n=6$ ) were determined with a modified Wilhelmy balance at room temperature. $\dagger$ The droplets $(2 \mu \mathrm{l})$ of the lipid dispersion $\left(2 \mathrm{mg} \mathrm{m}^{-1}\right)$ on a polystyrene surface were examined by the method of Mack (1935).

$\ddagger$ Mean of 10 determinations \pm SEM.

$\S$ Droplet diameter was not constant (see text).

\section{Isolation and characterization of vesicles}

$S$. marcescens cultures at $30^{\circ} \mathrm{C}$ were rich in extracellular vesicles, but it was difficult to separate native vesicles from bacterial cells due to the presence of many vesicle-carrying cells of intermediate density. In the course of fixation for electron microscopy, we noted that vesicles remained in the supernatant after the centrifugation of bacterial suspensions treated with glutaraldehyde. The vesicles thus obtained were mostly small (Fig. 9), and had strong wetting activity. Their main lipid component was the wetting agent, and the red pigment prodigiosin in the case of pigmented strain NS 38 (Fig. 8b). The lipid composition of the vesicles was quite different from that of the cell mass containing no vesicles $\left(37^{\circ} \mathrm{C}\right.$ culture $)$, but similar to that of the cell mass rich in vesicles $\left(30^{\circ} \mathrm{C}\right.$ culture).

\section{Chemical analysis of the wetting agents}

As found with the wetting agent W1, identified as serratamolide (Matsuyama et al., 1985), the wetting agents W2 and W3 showed no reaction with the Dittmer, anthrone or ninhydrin reagent, and produced ninhydrin-positive compounds after acid hydrolysis. W2 and W3, 


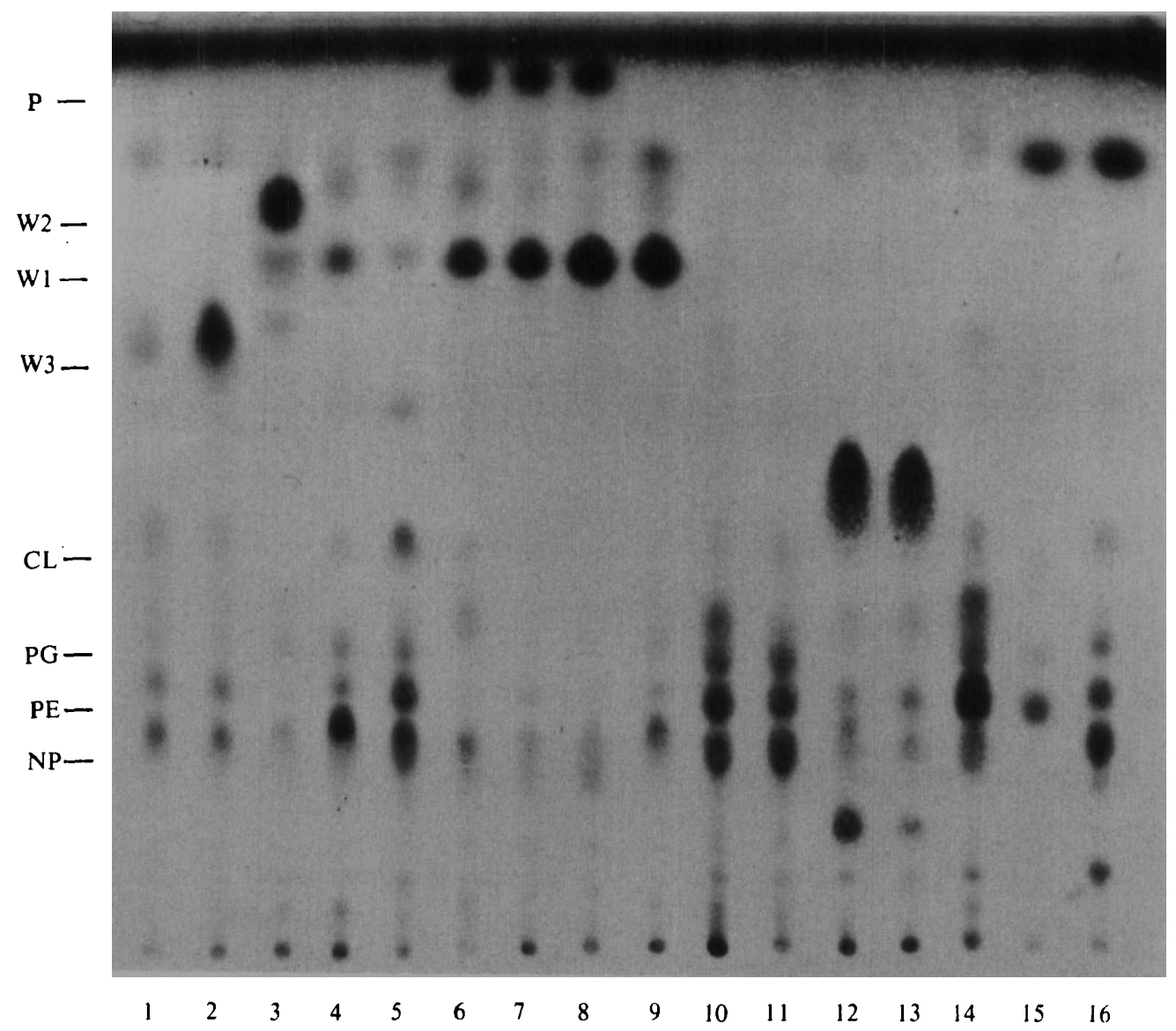

Fig. 7. Thin-layer chromatograms of lipids extracted from a $30^{\circ} \mathrm{C}$ culture of $S$. marcescens strains NS 33 (lane 1), NS 45 (lane 2), NS 25 (lane 3), NS 13 (lane 4), ATCC 8100 (lane 5), ATCC 13880 (lane 6), NS 12 (lane 7), NS 38 (lane 8) and 933 (lane 9); S. liquefaciens strains NCTC 10442 (lane 10) and CDC 1284-54 (lane 11): S. rubidaea strains ATCC 27593 (lane 12) and CDC 299-72 (lane 13); Enterobacter cloacae ATCC 23355 (lane 14); Escherichia coli K12S (lane 15); $P$. aeruginosa ATCC 10145 (lane 16). Each sample $(50 \mu \mathrm{g})$ was developed with a solvent of chloroform $/ \mathrm{methanol} / 5 \mathrm{M}$ ammonia $\left(80: 25: 4\right.$, by vol.). For detection of components, the plate was sprayed with $50 \%(\mathrm{v} / \mathrm{v}) \mathrm{H}_{2} \mathrm{SO}_{4}$ and heated at $200^{\circ} \mathrm{C}$ for $20 \mathrm{~min}$. NP, ninhydrin-positive unidentified lipid; PE, phosphatidylethanolamine; PG, phosphatidylglycerol; CL, cardiolipin; W1, W2 and W3, lipids with wetting activity; P, prodigiosin.

however, were different from the wetting agent W1 which was composed of 3-hydroxydecanoic acid and serine. Acid hydrolysates of the wetting agents $\mathrm{W} 2$ and $\mathrm{W} 3$ contained threonine and unidentified ninhydrin-positive compounds in addition to serine. Hexane-soluble methanolysates of $\mathrm{W} 2$ and $\mathrm{W} 3$ were found by GC/MS analyses to contain methyl esters of non-polar fatty acids $\left(C_{10}, C_{12}\right.$ or $\left.C_{14}\right)$. IR spectra of the wetting agent $W 1$ had strong absorption bands of ester linkage (at $1730 \mathrm{~cm}^{-1}$ ) and amide linkage (at 1540 and $1640 \mathrm{~cm}^{-1}$ ), whereas the IR spectra of the wetting agents $\mathrm{W} 2$ and $\mathrm{W} 3$ had a weak absorption band at $1730 \mathrm{~cm}^{-1}$ and strong bands at 1540 and $1640 \mathrm{~cm}^{-1}$. Thus, the wetting agents W2 and W3 were considered to be new compounds requiring further chemical characterization.

\section{DISCUSSION}

Colonies of most $S$. marcescens strains after overnight $(15 \mathrm{~h})$ growth at $30^{\circ} \mathrm{C}$ contained wetting agents and extracellular vesicles. As found for colony pigmentation by the secondary metabolite prodigiosin (Williams \& Qadri, 1980), wetting activity and extracellular vesicles 


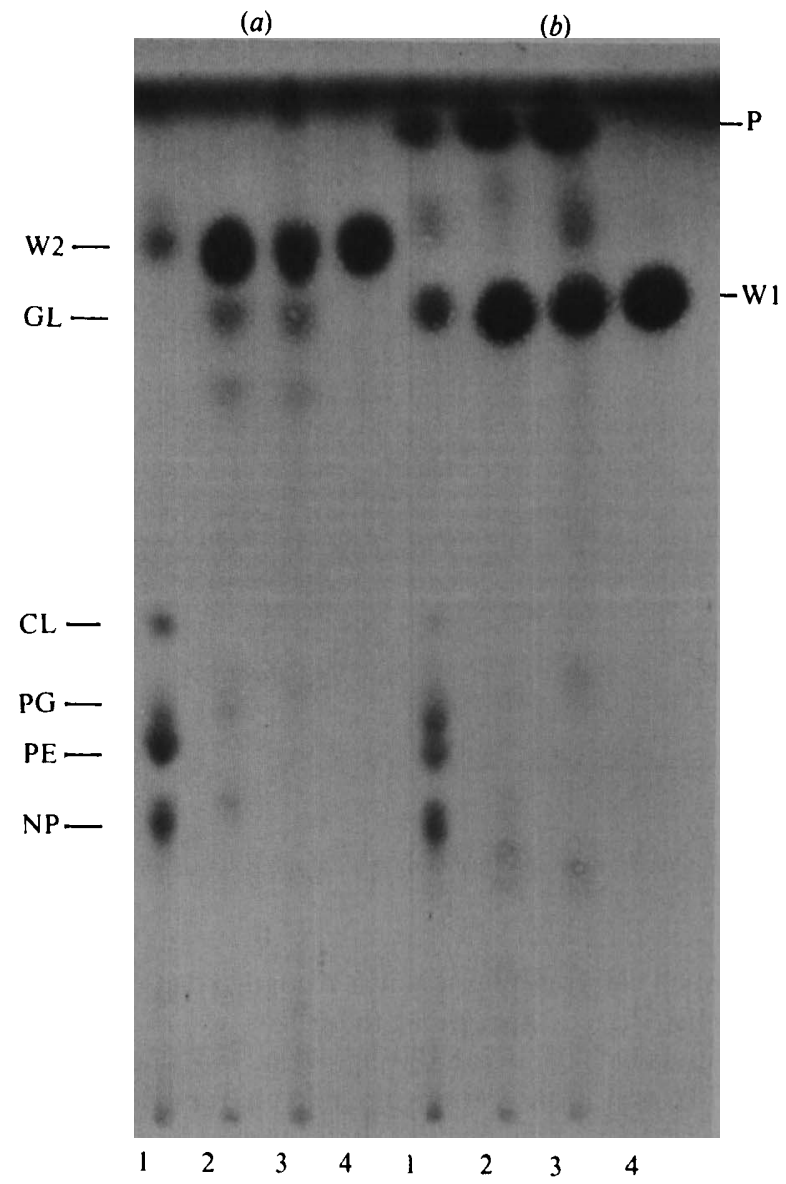

Fig. 8. Thin-layer chromatograms of lipids extracted from (a) $S$. marcescens NS 25 and (b) $S$. marcescens NS 38 . Lanes: $1,37^{\circ} \mathrm{C}$ culture; $2,30^{\circ} \mathrm{C}$ culture; 3 , isolated vesicles; 4 , W2 spot $(a)$ and W1 spot $(b)$. Each sample $(50 \mu \mathrm{g})$ was developed with a solvent of chloroform/methanol $/ 5 \mathrm{M}$-ammonia $\left(80: 25: 4\right.$, by vol.). For detection of components, the plate was sprayed with $50 \%(\mathrm{v} / \mathrm{v}) \mathrm{H}_{2} \mathrm{SO}_{4}$ and heated at $200{ }^{\circ} \mathrm{C}$ for $20 \mathrm{~min}$. Abbreviations as in Fig. 7 legend plus GL, unidentified glycolipid.

became more prominent during growth for a further $2 \mathrm{~d}$. So, in this study, 3-d-old cultures were used to examine these characteristics, and to isolate the wetting agents and extracellular vesicles efficiently.

After sonic disruption and fractionation of pigmented cells, Purkayastha \& Williams (1960) demonstrated that amounts of the pigment and hexosamine paralleled each other. By an electron microscopic examination, they also showed that fractions rich in pigment contained many cell envelopes. Thus, pigment localization in the cell envelope has been discussed by many investigators in relation to the marked cell-surface hydrophobicity of $S$. marcescens (Blanchard \& Syzdek, 1978; Hermansson et al., 1979; Kjelleberg et al., 1980; Rosenberg, 1981).

At the start of this study, we found minute red spots scattered in the agar around pigmented colonies of $S$. marcescens that had been grown on PG agar at $30^{\circ} \mathrm{C}$ for $3 \mathrm{~d}$ and then kept at room temperature for a further 3-5 d (unpublished observation). Despite repeated attempts, bacteria could not be grown from such spots, suggesting that the red material was extracellular. Direct microscopic observation of colonies surrounded by the red spots (Figs 2, $3 a$ and $3 b$ ) showed that pigment was localized in vesicles (extracellular and cell-associated) or intracellular granules. In accordance with this observation, isolated extracellular vesicles were shown to contain a considerable amount of prodigiosin (Fig. 8). Further characterization of extracellular vesicles is now in progress. For unknown reasons, liquid cultures of $S$. marcescens showing wetting activity 


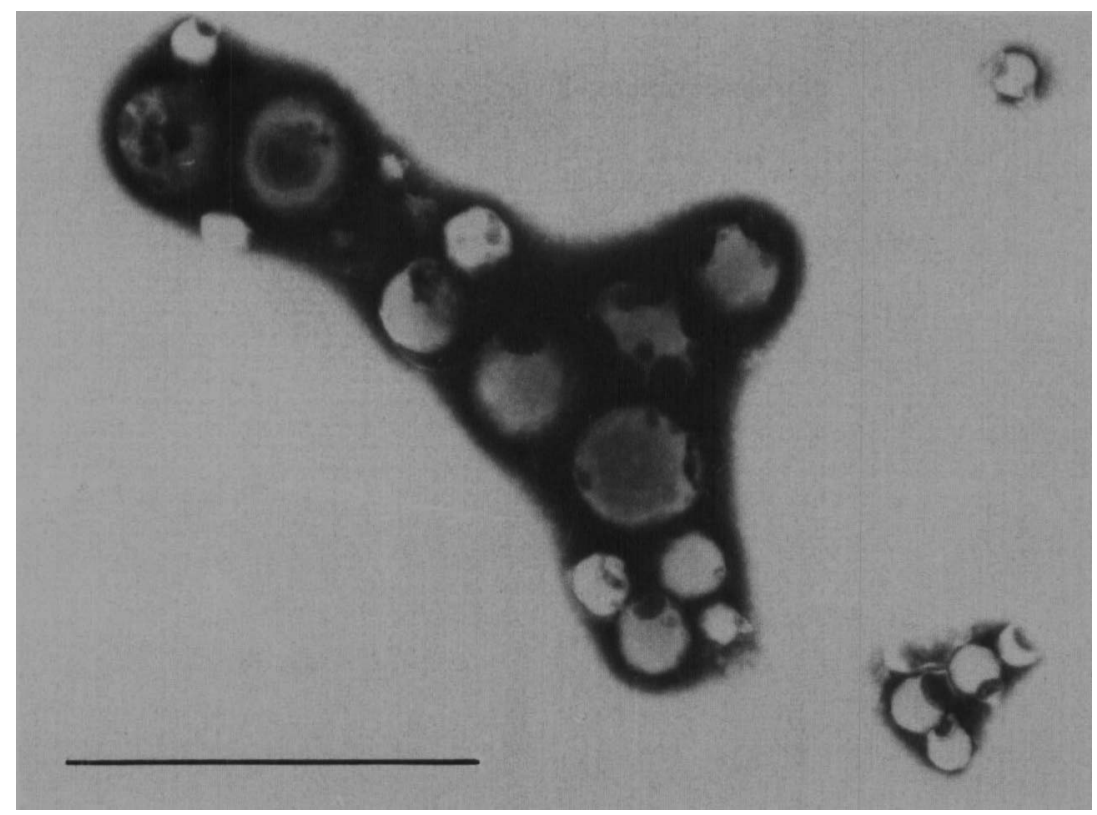

Fig. 9. Negative-stained electron micrograph of the isolated vesicles from a $30^{\circ} \mathrm{C}$ culture of $S$. marcescens NS 38. Bar, $1 \mu \mathrm{m}$.

contained few vesicles. In such cultures, pigment was recognized as only one or two red granular spots in the cell, but not distributed throughout the cell.

$S$. marcescens is a ubiquitous bacterium inhabiting water, soil, plants, insects and vertebrates (Grimont \& Grimont, 1978), and it has various notable characteristics. It is an opportunistic pathogen of humans, and a real threat in hospitals. Prolonged survival of $S$. marcescens adhering to the wall of plastic bottles filled with $2 \%$ chlorhexidine has been reported (Marrie \& Costerton, 1981). In addition to producing the red pigment prodigiosin (Williams \& Qadri, 1980), $S$. marcescens secretes many kinds of exoenzymes, such as nuclease, protease, lipase and chitinase (Winkler et al., 1978; Heller, 1979; Kole \& Altosaar, 1985). The extracellular vesicles released from the cell surface of pigmented $S$. marcescens were shown to contain prodigiosin at least but the contents of the extracellular vesicles released from non-pigmented strains are unknown. Although the aminolipids which are produced in parallel with vesicle formation were identified as wetting agents, their primary function is uncertain. Incorporation of this kind of aminolipid into the membrane lipids might modify membrane flexibility or cell-surface hydrophobicity. Wetting activity by itself seems to be important in spreading of cells on the surface of porous or fibrous materials, especially those having a hydrophobic property. Experimental studies regarding this point are now in progress.

The authors thank Drs T. Yoshida and Y. Uejima for their help in measuring surface tension and Mr S. Imaizumi and Miss Y. Machiya for their help in preparation of the manuscript.

\section{REFERENCES}

Blanchard, D. C. \& Syzdek, K. D. (1978). Seven problems in bubble and jet drop researches. Limnology and Oceanography 23, 389-400.

Grimont, P. A. D. \& Grimont, F. (1978). The genus Serratia. Annual Review of Microbiology 32, 221-248.

Heller, K. B. (1979). Lipolytic activity copurified with the outer membrane of Serratia marcescens. Journal of Bacteriology 140, 1120-1122.
Hermansson, M., Kjelleberg, S. \& Norkrans, B. (1979). Interaction of pigmented wildtype and pigmentless mutant of Serratia marcescens with lipid surface film. FEMS Microbiology Letters 6, 129-132.

KaWal, Y. \& YaNo, I. (1983). Ornithine-containing lipid of Bordetella pertussis, a new type of hemagglutinin. European Journal of Biochemistry 136, 531 538. 
KJelleberg, S., Lagercrantz, C. \& Larsson, Th. (1980). Quantitative analysis of bacterial hydrophobicity studied by the binding of dodecanoic acid FEMS Microbiology Letters 7, 41-44.

Kobayashi, T., Grossman, G., Robertson, B. \& UEDA, T. (1984). Effects of artificial and natural surfactant supplementation in immature newborn rabbits. Journal of the Japanese Medical Association of Biological Interface 15, 53-59.

Kole, M. M. \& AltosaAR, I. (1985). Increased chitinase production by a non-pigmented mutant of Serratia marcescens. FEMS Microbiology Letters 26, 265-269.

MACK, G. L. (1935). The determination of contact angles from measurements of the dimensions of small bubbles and drops. I. The spheroidal segment method for acute angles. Journal of Physical Chemistry 40, 159-167.

Marrie, T. J. \& Costerton, J. W. (1981). Prolonged survival of Serratia marcescens in chlorhexidine. Applied and Environmental Microbiology 42, 10931102.

Matsuyama, T. (1977). Resistance of Bordetella pertussis phase I to mucociliary clearance by rabbit tracheal mucous membrane. Journal of Infectious Diseases 136, 609-616.

Matsuyama, T., Fujita, M. \& Yano, I. (1985). Wetting agent produced by Serratia marcescens. FEMS Microbiology Letters 28, 125-129.

MuRAKAMI, T. \& MATSUyama, T. (1980). Growth of
Bacteroides fragilis inoculated on rabbit tracheal explant in an atmospheric environment. Journal of Infectious Diseases 142, 332-337.

Ohno, Y., Yano, I., Hiramatsu, T. \& Masui, M. (1976). Lipids and fatty acids of a moderately halophilic bacterium, no. 101. Biochimica et biophysica acta 424, 337-350.

Purkayastha, M. \& Williams, R. P. (1960). Association of pigment with the cell envelope of Serratia marcescens (Chromobacterium prodigiosum). Nature, London 187, 349-350.

ROSENBERG, M. (1981). Bacterial adherence to polystyrene: a replica method of screening for bacterial hydrophobicity. Applied and Environmental Microbiology 42, 375-377.

W asserman, H. H., KegGi, J. J. \& McKeon, J. E. (1961). Serratamolide, a metabolic product of Serratia. Journal of the American Chemical Society 83, 4107-4108.

Wasserman, H. H., KegGi, J. J. \& McKeon, J. E. (1962). The structure of serratamolide. Journal of the American Chemical Society 84, 2978-2982.

Williams, R. P. \& QADRI, S. M. H. (1980). The pigment of Serratia. In The Genus Serratia, pp. 3175. Edited by A. von Graevenitz \& S. J. Rubin. Boca Raton, Florida: CRC Press.

Winkler, U., Heller, K. B. \& Folle, B. (1978). Pleiotropic consequences of mutations towards antibiotic-hypersensitivity in Serratia marcescens. Archives of Microbiology 116, 259-268. 